\title{
Minding the Shop: The Case of Obstetrics Conferences ${ }^{*}$
}

\author{
Joshua S. Gans \\ Melbourne Business School \\ University of Melbourne \\ www.mbs.edu/jgans \\ J.Gans@unimelb.edu.au \\ Andrew Leigh \\ Research School of Social Sciences \\ Australian National University \\ http://econrsss.anu.edu.au/ aleigh/ \\ andrew.leigh@anu.edu.au \\ Elena Varganova \\ Research School of Social Sciences \\ Australian National University \\ elena.varganova@anu.edu.au
}

This Version: December 2, 2006

\begin{abstract}
We estimate the impact of annual obstetricians and gynecologists' conferences on births in Australia and the United States. In both countries, the number of births drops by 1 to 4 percent during the days on which these conferences are held. We argue that for this reason professional obstetrics societies should reconsider the timing of their annual conferences to accommodate the lowest natural birth rate in the year.
\end{abstract}

Journal of Economic Literature Classification Numbers: I12, J13, J44

Keywords: timing of births, medical care, obstetrics, conference scheduling.

\footnotetext{
* We are grateful to Kylie Grose of the Royal Australian and New Zealand College of Obstetricians and Gynaecologists and Paul Sutton of the National Center for Health Statistics for assistance in obtaining the necessary data. These people should not be assumed to agree with the contents of this paper. All errors are ours.
} 


\section{Introduction}

In most professional occupations, annual conferences have become a routine form of on-the-job training. Coordinating large-scale meetings has efficiency gains, and permits new information to be disseminated from experts to the rest of the profession.

In the medical profession, the rapid advent of technological change and innovation has resulted in annual conferences becoming a normal part of the career of many physicians, particularly those in specialist fields. While these conferences have clear advantages, in the form of knowledge transfer, little has been written about how hospitals and others manage the consequent shock to the supply of available medical personnel.

When there is a forecast shock to personnel supply there are two possible mitigating actions that can be taken. The first would be with regard to conference scheduling: that is, conferences could be scheduled for natural downtimes where demand for services is more limited. We see this, for instance, in academic conferences which are typically scheduled for summer or semester breaks. ${ }^{1}$ The second action would be to alter demand itself around the conference date. Schedules would be adjusted so that overloads are taken just prior and just after the conference with reduced services for its duration.

This paper provides an insight into the use of these two mechanisms with regard to the practices of obstetricians and gynecologists in both the United States and Australia. By using data from two countries we reduce the likelihood that our results are driven by idiosyncratic factors specific to one nation; but it also provides the opportunity to compare the magnitude of our estimated effects. We find some similarities but also

\footnotetext{
${ }^{1}$ For example, the annual meetings of academic economists in the US (the ASSA Meetings) are traditionally held over the first weekend of the year; a week before Winter term teaching commences.
} 
significant disparities between the two countries in their management of demand around the annual professional conferences of obstetricians and gynecologists (henceforth 'obstetrics conferences'). In each case, the conference itself has an impact on the daily birth rate (reducing it by between 1 and 4 percent). However, in the United States, the conference is scheduled for a relatively low demand period while in Australia, in recent times, the opposite has occurred.

The endogeneity of the birth rate comes from technologies that allow the timing of births to be manipulated. In practice, the two main ways in which the timing of births can be moved is via decisions about when inducement procedures and elective cesarean section procedures will be carried out. Our result on the conference impact on birth timing adds to the literature on the extent to which such timing can be affected by nonmedical factors. Parents have been shown to seek out auspicious birth dates (Lo 2003) avoid inauspicious birth dates (Gans and Leigh 2006a; Lin, Xirasagar and Yu-Chi Tung 2006), and time childbirth so as to receive tax credits and special payments (DickertConlin and Chandra 1999; Gans and Leigh 2006b). Physicians have been shown to make decisions on births (in particular, whether to carry out a cesarean section) that are affected by their own demand for leisure (Brown 1999). The impact of conferences relates to the short-term interests of the physicians in these decisions and shows they have discretion as to birth timing so as to fit their schedules.

The paper proceeds as follow. Section 2 describes the data. Section 3 examines the relationship between conference timing and the overall birth rate. Section 4 presents results on endogenous birth timing, and the final section concludes. 


\section{Data}

Our measure of the demand for obstetrics services is daily birth counts (specifically, our dependent variable in regressions report is the log of the number of babies born each day). ${ }^{2}$ For Australia, we obtain the daily birth count from the Australian Bureau of Statistics. For the United States, we obtain daily birth count data from the National Center for Health Statistics. The US data are based on a partial sample of birth records prior to 1984, and a full tabulation from 1985 onwards.

In the two countries, we identified the largest conferences of obstetricians and gynecologists. In Australia, this is the annual scientific meeting of the Royal Australian and New Zealand College of Obstetricians and Gynaecologists. In the United States, this is the annual meeting of the American College of Obstetricians and Gynecologists. For both countries, we omit nationally observed public holidays. Dates of the obstetrics conferences and a list of the excluded public holidays are provided in the Data Appendix.

The sample of years differs for the two countries. For Australia, we are limited by the availability of dates for the annual obstetrics conferences, which were only available for 1990-2003. For the United States, we were limited by the availability of daily birth count data, which were only available for 1969-2001. We therefore present specifications using all available data, and restricting the sample to the common years 1990-2001.

For Australia (1990-2003), the mean for $\log$ (births) is 6.5, and the standard deviation is 0.18. For the United States (1969-2001), the mean for log(births) is 9.2, and the standard deviation is 0.15. Over the common years (1990-2001), the mean for $\log$ (births) in Australia is 6.5 and the standard deviation is 0.18 , while in the United

\footnotetext{
${ }^{2}$ Our results are robust to alternative specifications, such as using the unlogged number of births, or the birth rate.
} 
States, the mean for $\log$ (births) is 9.3 , and the standard deviation is 0.17 . Across the full Australian sample, obstetrics conferences are between 3 and 6 days long, with a mean duration of 4.64 days. Across the full United States sample, obstetrics conferences are between 4 and 7 days long, with a mean duration of 5.70 days. In the common years (1990-2001), conference duration is more similar: 4.75 days for Australia and 5.25 days for the United States.

\section{The Timing of Obstetrics Conferences}

To build a picture of how obstetrics conferences are dealt with, it is useful first to examine their timing. In both Australia and the United States there is considerable seasonal variation in birth rates. In Australia, births have a peak at the end of March (autumn) and late-September (spring). In the United States, births also peak in midMarch (spring) and late-September (fall). There is also a trough in births in both countries in the Christmas-New Year period with a minor peak a few weeks earlier.

Figures 1 and 2 plot the daily birth rates against the dates there were conferences for the full and common samples respectively. For the United States, conferences are timed a few weeks after the April trough with a regular conference in May. For Australia, conferences have occurred throughout the year. However, in the last few years, they have been timed around October - at the peak birth rate time.

To make this more precise, we assigned each day of the year a percentile rank, according to the average number of births that occurred on that day. Thus the day of the year with the fewest number of births is at the 1st percentile, the day of the year with the most births is at the 100th percentile, and the typical day is at the 50th percentile. We 
then estimated where obstetrics conference dates fell in the overall daily births distribution. Over the full sample, the typical Australian conference was held on a day that was at the 67th percentile (ie. a relatively high-birth time of the year), while the typical United States obstetrics conference was held on a day at the 19th percentile (ie. a relatively low-birth time of the year). Over the common sample (1990-2001), the typical Australian conference took place on a day of the year that was at the 58th percentile of the births distribution, while the typical United States obstetrics conference was held on a day of the year that was at the 43rd percentile of the births distribution. 
Figure 1: Are Conference Dates Timed to Minimize Disruption? (Full Sample)
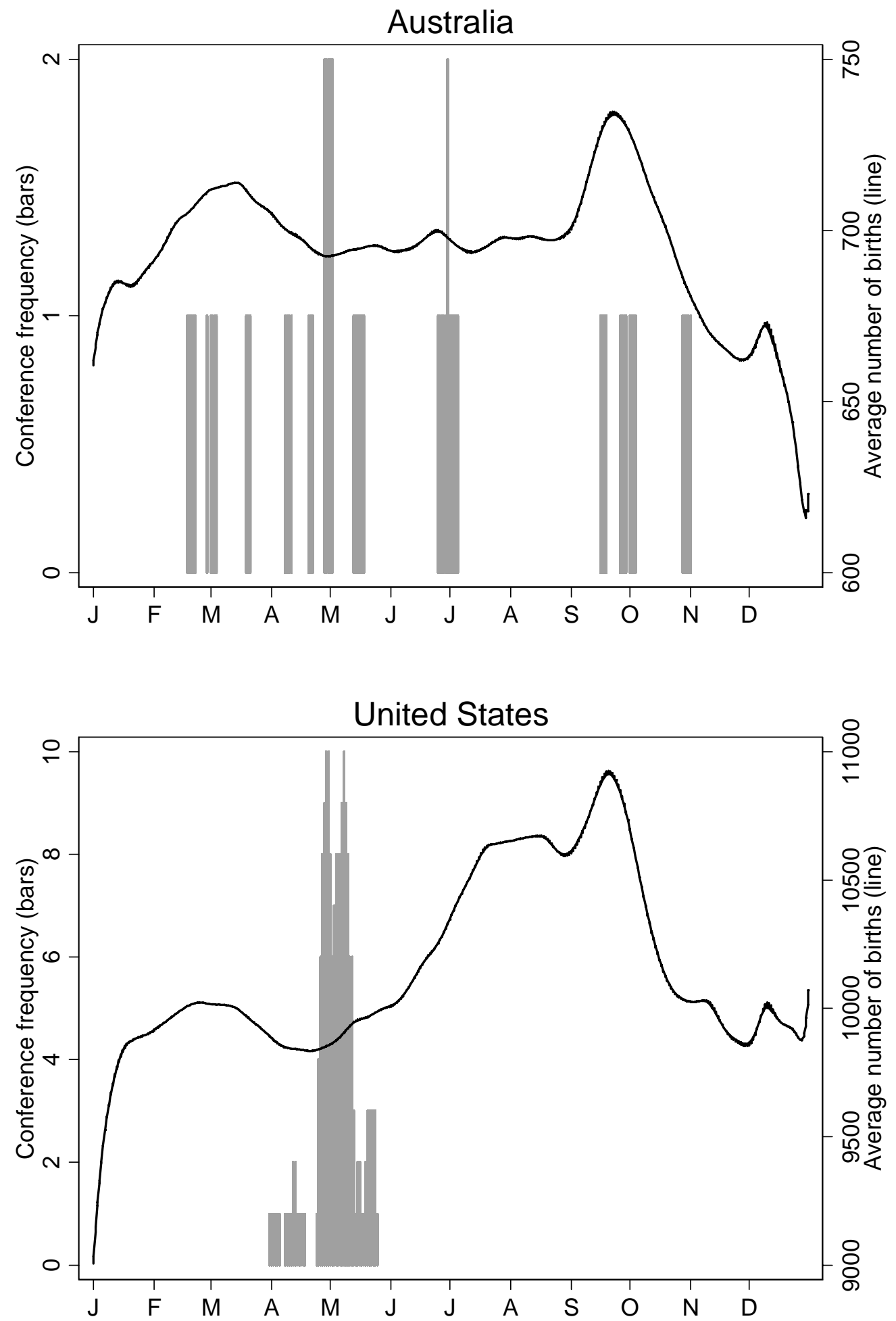

Note: We calculate the mean number of births for each day of the year, and then chart this as a lowess plot. Conference frequency is the number of times during the sample period that a conference has been held on that particular day of the year (eg. April 15). 
Figure 2: Are Conference Dates Timed to Minimize Disruption? (1990-2001)
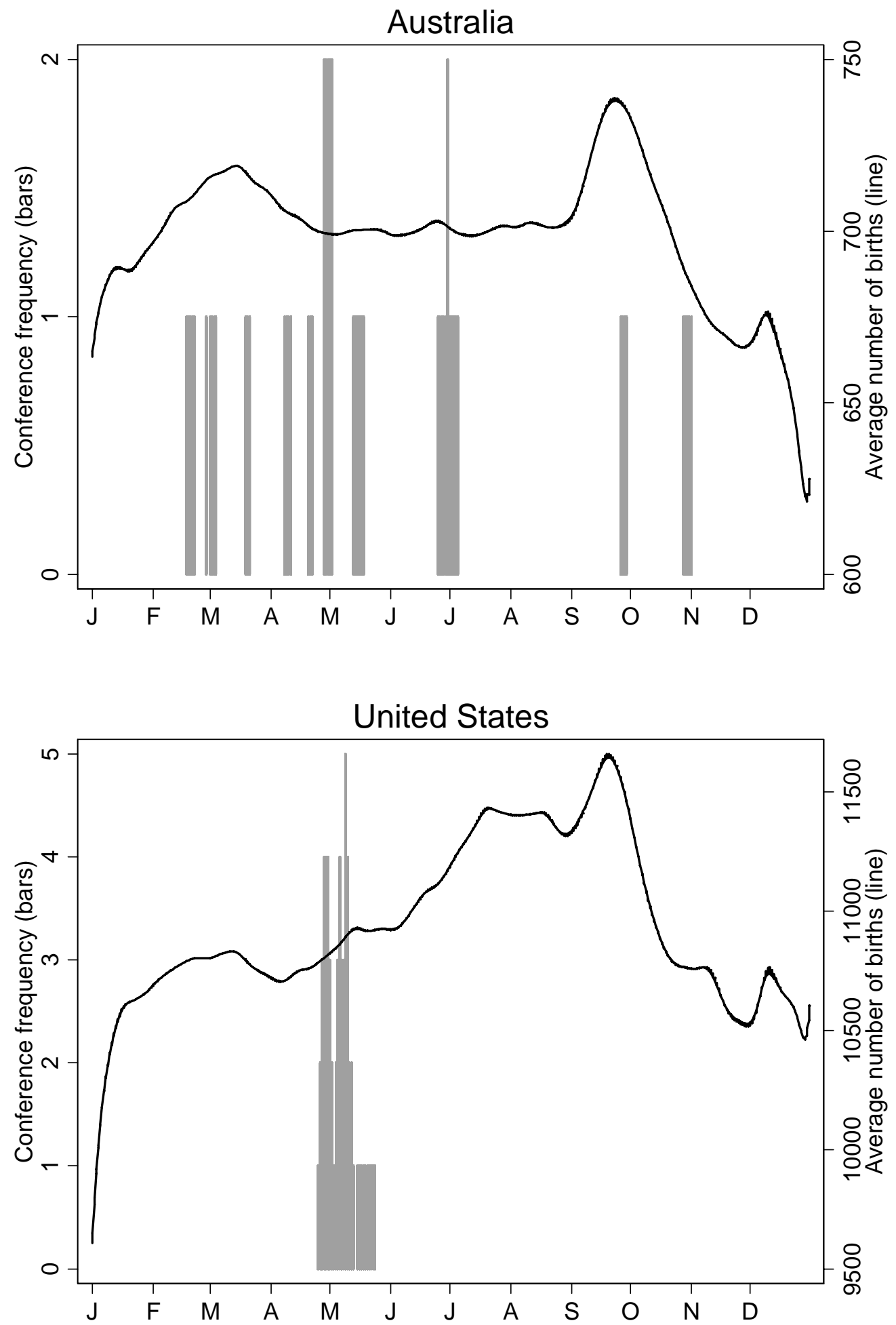

Note: We calculate the mean number of births for each day of the year, and then chart this as a lowess plot. Conference frequency is the number of times during the sample period that a conference has been held on that particular day of the year (eg. April 15). 
Conference date selection can depend upon a number of factors including venue availability and other considerations (e.g., weather). They can also be impacted upon by the timing of other local conferences and also, in the case of Australia, international ones.

Considering birth rates alone, the optimal conference timing in both countries would be at the end of December for Australia, and the beginning of January for the United States. However, it is clear from these graphs that the US comes closer to a local minimum in selecting its conference time than does Australia, where the conference is scheduled for a relatively high-birth time of the year. The next section explores whether birth rates ought to be a factor in determining conference timing.

\section{The Effect of Obstetrics Conferences on Births}

The birth rate itself should only be a factor in selecting the timing of obstetrics conferences if those conferences were themselves potentially disruptive to medical decision making. In particular, if the timing of births was significantly different around the conference date compared with other times of the year, this would be evidence that the conference itself was costly and hence that care should be taken in determining its timing.

To see the effect of obstetrics conferences on births, we regress daily births on indicator variables for the days before the conference, during the conference, and after the conference, plus a rich set of time controls. Our regressions take the following form:

$$
\begin{gathered}
\text { Births }_{i}=\alpha+\beta * \text { BeforeConf }_{i}+\gamma^{*} \text { DuringConf }_{i}+\delta^{*} \text { AfterConf }_{i}+I_{i}^{\text {Dayofweek }} \\
+I_{i}^{\text {DayofYear }}+I_{i}^{\text {Year }}+\varepsilon_{i}
\end{gathered}
$$


Where BeforeConf is an indicator variable for the 5 days before an obstetrics conference, DuringConf is an indicator variable for the days on which the conference takes place, and AfterConf is an indicator variable for the 5 days after an obstetrics conference. The regression also includes fixed effects for the day of the week (eg. Monday, Tuesday), the day of the year (eg. May 1, May 2), and the calendar year. Our results are therefore identified from differences in the number of births on days during, before and after an obstetrics conference, taking account of the day of the week, the time of the year, and year effects. Estimates are from an ordinary least squares regression. ${ }^{3}$

The results of our regressions are shown in Table 1. Columns 1 and 3 show the full sample for Australia and the United States, respectively. In the years 1990-2003, obstetrics conferences in Australia were associated with a 3.6 percent fall in births. In the years 1969-2003, obstetrics conferences in the United States were associated with a 1.3 percent fall in births. In both cases, the indicator variable for the pre-conference period is positive, but it is only statistically significant for United States. The coefficient on the indicator variable for the post-conference period is close to zero and statistically insignificant.

\footnotetext{
${ }^{3}$ Our results are robust to using Newey-West standard errors, to take account of possible autocorrelation in the dependent variable.
} 


\begin{tabular}{lcccc}
\hline \multicolumn{5}{l}{ Table 1: Do Obstetrics Conferences Affect Births? } \\
\multicolumn{5}{l}{ Dependent Variable: Log(Births) } \\
\hline & {$[1]$} & {$[2]$} & {$[3]$} & {$[4]$} \\
& Australia & Australia & US & US \\
5 days before conference & $1990-2003$ & $1990-2001$ & $1969-2001$ & $1990-2001$ \\
& 0.003 & -0.001 & $0.010^{* *}$ & 0.010 \\
During conference & {$[0.007]$} & {$[0.007]$} & {$[0.005]$} & {$[0.007]$} \\
& $-0.036^{* * *}$ & $-0.038^{* * *}$ & $-0.013^{* * *}$ & $-0.015^{* *}$ \\
5 days after conference & {$[0.007]$} & {$[0.007]$} & {$[0.004]$} & {$[0.007]$} \\
& -0.001 & 0.001 & 0.000 & 0.004 \\
Observations & {$[0.007]$} & {$[0.007]$} & {$[0.005]$} & {$[0.008]$} \\
R-squared & 5015 & 4299 & 11723 & 4263 \\
\hline
\end{tabular}

Note: All specifications include fixed effects for day of week, day of year, and year. Public holidays are excluded from the regressions. Standard errors in brackets. * significant at 10\%; ** significant at 5\%; *** significant at $1 \%$. The difference in sample size between columns 2 and 4 reflects differences in the number of nationally-observed public holidays.

To give some sense of the magnitude of these effects, the results in Table 1 suggest that the average obstetrics conference in Australia leads to 116 babies being born on a different date than if the conference had not taken place, while the average obstetrics conference in the United States leads to 755 babies being born on a different date than if the conference had not taken place. In columns 2 and 4, we restrict the sample to the common period in the data (1990-2001). In this specification, the coefficients for both countries remain similar in magnitude to the results from the full sample, and statistically significant.

Since the specifications in Table 1 constrain the effects of obstetrics conferences to be the same in each of the three periods, we now estimate a more flexible specification, including a separate indicator variable for each of the 5 days before the conference, the 6 
days during the conference, and the 5 days after the conference. ${ }^{4}$ This involves estimating the following regression:

$$
\begin{gathered}
\text { Births }_{i}=\alpha+\sum_{n=1}^{5} \beta^{n} \text { BeforeConf }_{i}^{n}+\sum_{n=1}^{6} \gamma^{n} \text { DuringConf }_{i}^{n}+\sum_{n=1}^{5} \delta^{n} \text { AfterConf }_{i}^{n} \\
+I_{i}^{\text {Dayofweek }}+I_{i}^{\text {DayOfYear }}+I_{i}^{\text {Year }}+\varepsilon_{i}
\end{gathered}
$$

In Figures 3 and 4, we plot the coefficients from this regression, and their 90 percent confidence intervals. In this more flexible specification, most of the coefficients are not statistically distinguishable from zero at conventional levels. However, the figures provide suggestive evidence that for Australia, the decrease in births is largest earlier in the conference, while for the United States, the decrease is larger later in the conference. Prior to the conference, the increase in births appears to be the same across the five day period; but we find suggestive evidence of a slight increase in births in the two days immediately after the conference (indicative perhaps of inducement procedures that had been held over during the conference).

\footnotetext{
${ }^{4}$ The United States obstetrics conference ran for 7 days in only one year, 1970. We ignore the final day of the 1970 conference in this part of our analysis.
} 


\section{Figure 3: Obstetrics Conferences \\ (All Available Years)}

Australia (1990-2003)

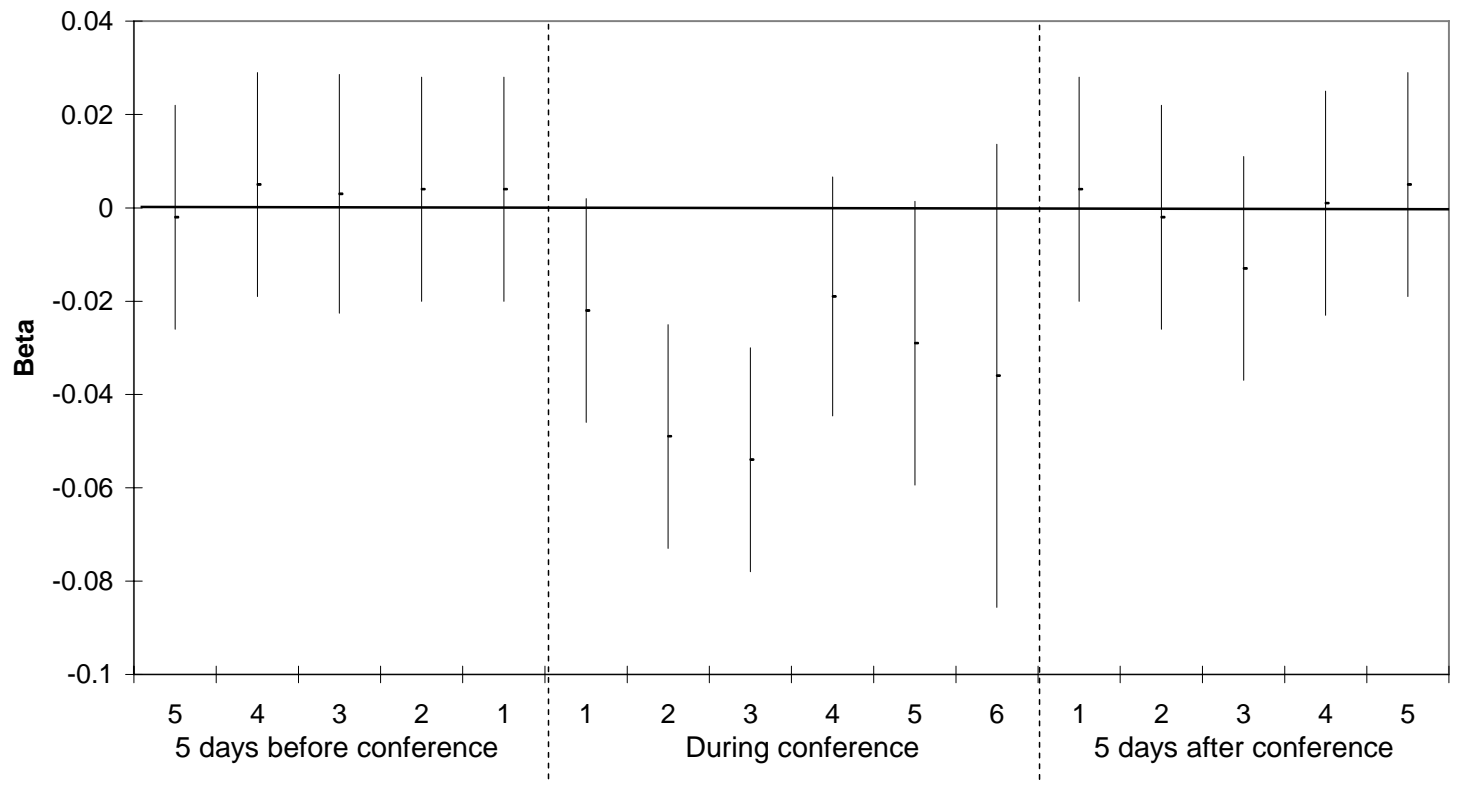

United States (1969-2001)

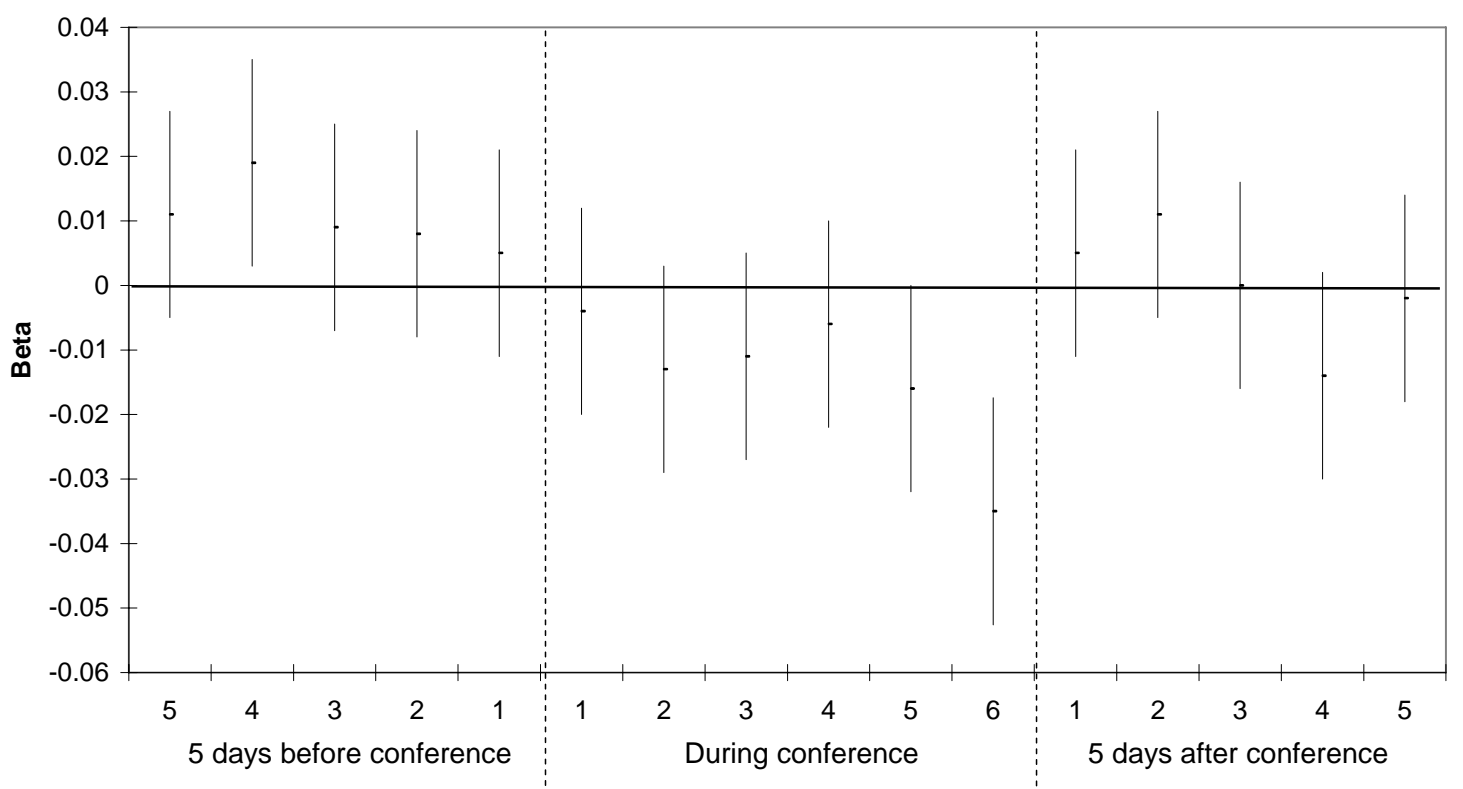

Note: Dots denote the point estimates from a regression of $\log$ (births) on the 16 indicator variables shown, plus day of week, day of year, and year fixed effects. Intervals show 90 percent confidence ranges. 


\section{Figure 4: Obstetrics Conferences (1990-2001)}

Australia (1990-2001)

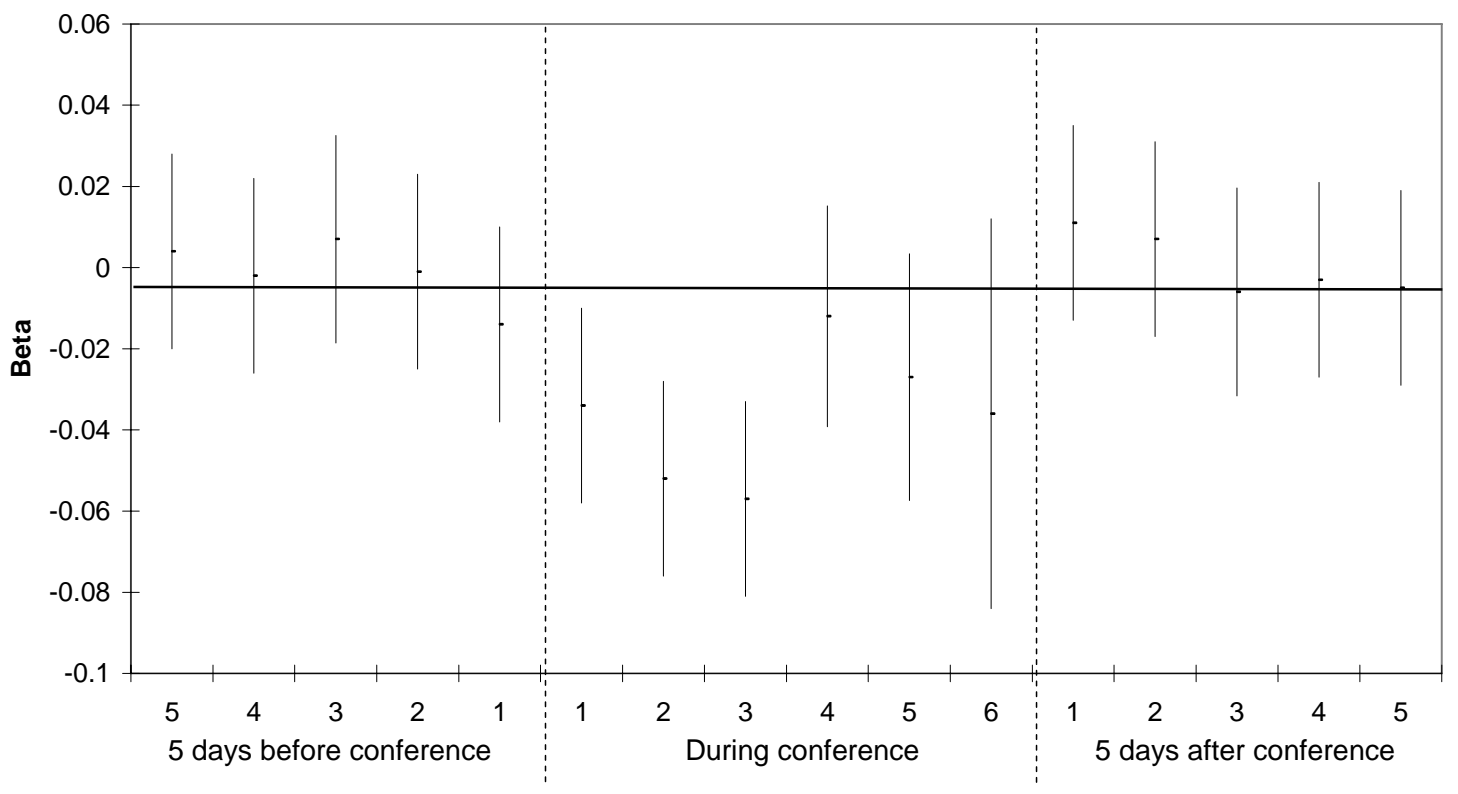

\section{United States (1990-2001)}

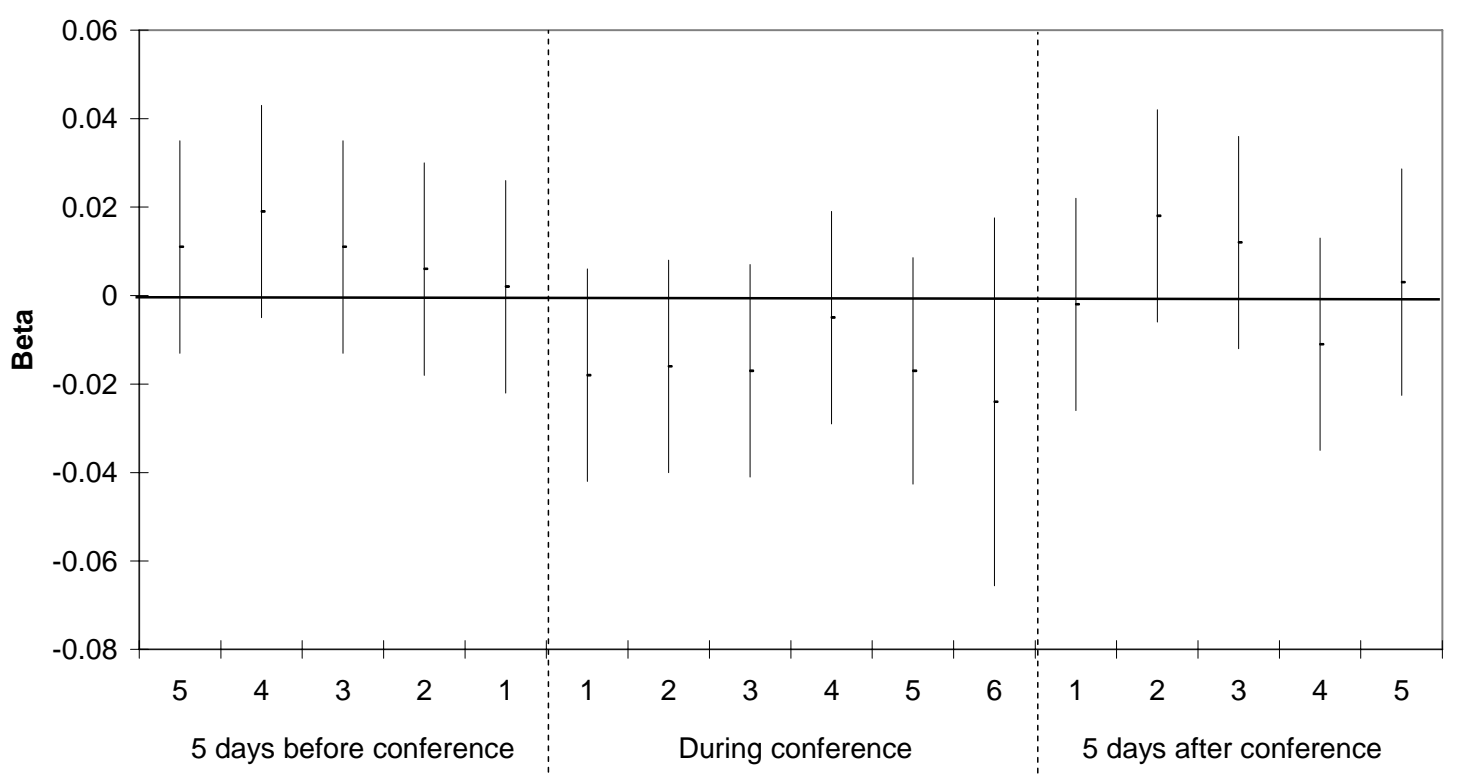

Note: Dots denote the point estimates from a regression of log(births) on the 16 indicator variables shown, plus day of week, day of year, and year fixed effects. Intervals show 90 percent confidence ranges. 
It is difficult to explain the fact that the 'obstetrics conference effect' is larger for Australia than the United States? It does not appear to be accounted for by any differences in sample selection, since the results are largely unchanged when the common years are used. There is a difference in conference length with the Australian conferences averaging 4.64 days and the United States 5.69. However, a shorter conference length would usually be thought to generate a smaller rather than a larger effect. Of course, the United States conference typically did not include a Friday whereas the Australian conferences typically did not include weekend days. If Australian participants stayed on for the weekend, the effective conference lengths might be similar.

One plausible explanation for the cross-country difference is that a larger share of obstetricians and gynecologists attend the annual conference in Australia than in the United States (though because we have been unable to obtain data on attendance as a share of the profession, this remains speculative). ${ }^{5}$ An alternative possibility is that physicians in Australia are more willing than their United States counterparts to move births to suit the timing of their professional development.

As a final explanation, there could be an interaction between the natural birth rate at the time of the conference and the ability to shift births. There is little variation in the United States conference timing but with Australia the timing has shifted considerably over the years. However, when we use the common sample and run our baseline regressions with an interaction effect for the seasons, we find this to be statistically insignificant and our estimated coefficients - specifically on the conference effect - to be approximately the same as our baseline result. Consequently, we do not find evidence

\footnotetext{
${ }^{5}$ We also examined whether the timing of the United States conference had an impact on Australian birth timing and found no effect.
} 
that the magnitude of the conference effect differs depending upon variation in the natural birth rate around the time of the conference.

\section{Conclusion}

In both Australia and the United States, we find that the number of births falls during obstetrics conferences. Since it is unlikely that parents take these conferences into account when conceiving their child, this suggests that medical professionals are timing births to suit their conference schedule.

Although little is known about the effects on infant health of moving the timing of a birth for non-medical reasons, it is plausible that such changes may increase the chance of birth complications. In this instance, the increased risk to infant health is likely to be small, since most movements are likely to be small (one week or less), and appear to have been anticipated - as evidenced by the rise in births prior to the conference.

This suggests that obstetrics conference organizers, and those in Australia in particular, should change their conference dates, holding them at times of the year when the natural birth rate is at a minimum. Taking public holidays into account, this suggests that the Australian conference should be scheduled in the last week of November or the first week of December, and the United States conference should be held either in the last week of November or the first week of January.

We should also stress that while our results imply a small cost of obstetrics conferences, this does not imply that their net effect is detrimental with respect to infant health. Such a calculus would require a careful comparison of the risks to babies born at 
the time of the conference, against the benefits of the increased knowledge gleaned from obstetrics conferences. 


\section{References}

Brown III, H. S. (1996), "Physician demand for leisure: Implications for cesarean section rates,” Journal of Health Economics, 15, pp.223-242.

Dickert-Conlin, S. and A. Chandra (1999), “Taxes and the Timing of Births,” Journal of Political Economy, 107 (1), pp.161-177.

Gans J. S. and Leigh A. (2006a), "Bargaining over Labor: Do Patients have any Power?,” mimeo, Melbourne Business School

Gans, J.S. and A. Leigh (2006b), "Born on the First of July: An (Un)natural Experiment in Birth Timing,” mimeo, Melbourne Business School.

Lin H-C., Xirasagar S., and Tung Y-C. (2006), "Impact of a cultural belief about ghost month on delivery mode in Taiwan,” Journal of Epidemiological Community Health, 60, pp.522-526.

Lo, J.C. (2003), “Patient Attitudes vs. Physicians' Determination: Implications for Cesarean Sections," Social Science and Medicine, 57, pp.91-96. 


\section{Data Appendix}

\section{Obstetrics Conference Dates - Australia}

The Royal Australian and New Zealand College of Obstetricians and Gynaecologists held its annual scientific meetings on the following dates: May 13-18, 1990; February 18-22, 1991; April 8-11, 1992; March 19-21, 1993; April 20-22, 1994; September 26-29, 1995; June 30-July 5, 1996; April 28-May 2, 1997; April 28-May 2, 1998; February 28-March 4, 1999; June 25-30, 2000; October 28-November 1, 2001; October 1-4, 2002; September 16-19, 2003.

Source: Kylie Grose, Executive Officer of The Royal Australian and New Zealand College of Obstetricians and Gynaecologists.

\section{Obstetrics Conference Dates - United States}

The American College of Obstetricians and Gynecologists held meetings on the following dates: April 26-May 1, 1969; April 12-18, 1970; May 1-4, 1971; April 29-May 4, 1972; May 19-24, 1973; April 27-May 2, 1974; May 3-8, 1975; May 8-13, 1976; May 7-12, 1977; April 8-13, 1978; March 31-April 5, 1979; May 3-8, 1980; April 25-30, 1981; April 24-29, 1982; May 7-12, 1983; May 5-10, 1984; May 11-16, 1985; May 3-8, 1986; April 25-30, 1987; April 30-May 5, 1988; May 20-25, 1989; May 5-10, 1990; May 4-9, 1991; April 25-30, 1992; May 1-6, 1993; May 9-12, 1994; May 6-10, 1995; April 27-May 1, 1996; April 26-30, 1997; May 9-13, 1998; May 15-19, 1999; May 20-24, 2000; April 28-May 2, 2001.

Source: http://www.acog.org/departments/dept_notice.cfm?recno=21\&bulletin=965

\section{Public Holidays - Australia}

In Australia, nationally observed public holidays are: New Year's Day, Australia Day, Anzac Day, Good Friday, Easter Monday, Christmas Day and Boxing Day.

\section{Public Holidays - United States}

In the United States, nationally observed public holidays are: New Year's Day, Martin Luther King Jr Day, Presidents’ Day, Memorial Day, July 4, Labor Day, Columbus Day, Veteran's Day, Thanksgiving and Christmas Day. 